\title{
Developing the Digital Content Industry in Taiwan
}

\author{
Hsin-Hann Tsai \\ National Chiao Tung University \\ Hong-Yuh Lee \\ National Chiao Tung University \\ Hsiao-Cheng $\mathrm{Yu}$ \\ National Chiao Tung University
}

\begin{abstract}
The average global annual growth rate of digital content products has grown exponentially. This is because of the technology advancement, cost reduction, and availability of the enabling technologies, e.g., digital processing, digital storage, and digital telecommunications. The development of the digital content industry (DCI) requires a strong cultural background, creative ideas, respect of intellectual property rights, and telecommunications infrastructure, which are all dependent on government supportive policies. This study summarizes the government policies, progress, and obstacles in the development of Taiwan's DCI and compares these subjects with other countries, including the United States, EU countries, Japan, and Korea. In this paper, Taiwan's DCI opportunities and challenges will be discussed, and strategies and recommendations will be provided, based on Taiwan's unique resources and competitive advantages.
\end{abstract}

KEY WORDS: digital content, content creation, content distribution, digital archives, wireless content

\section{Introduction}

The knowledge-based economy is different from the manufacturing-orientated information communications technology (ICT) industry or the service industry because it emphasizes knowledge innovation and relies on different modes of production, technology, knowledge, innovation capacity, investment capital, and continuous creativity. The speed of technology innovation and new ideas are the key success factors, since the risks of knowledge becoming obsolete are high. Fast development of new knowledge and innovative technology can accelerate the evolution of existing goods. The speed of production becomes faster as new knowledge leads to formation of new technology. As a result, technologies and products that are rapidly changing will enhance competition among enterprises.

Enterprises will have to adjust their strategies in accordance with the changes in the knowledge-based economy. First, developing innovations earlier than competitors is key for market leadership, and accelerating innovation is necessary for improving time to market. Second, IIS (Innovational Intensive Service, Cheng \& Shyu, 2004) is the trend of the ICT industry in the knowledge-based economy; i.e., enterprises leverage market domination through innovative technology and use new service models to develop diversified products, services, and market expandability. Last but not least, the innovation process in the knowledge-based economy is considered pioneering and radical (Shyu, Cheng, \& Lai, 2005; Zahra, 1996), and the industrial environment is highly dynamic, hostile, and has low heterogeneity. ${ }^{1}$ Hence, enterprises in this environment profit by continuous innovation and diversified products.

Review of Policy Research, Volume 25, Number 2 (2008)

(C) 2008 by The Policy Studies Organization. All rights reserved. 
The digital content industry (DCI) digitalizes pictures, texts, videos, audios, and data and compiles them as one, which differs from other ICT industries. These digitalized pictures, texts, videos, audios, and data are integrated to become new products or services. Compared with other ICT value chains, the DCI is undergoing rapid changes. Many creative companies and organizations are engaged in the production and distribution of digital content because of the general usefulness of new technologies. These companies are increasingly being used in traditional industries, thus blurring the definition of some sectors (Allen Consulting Group, 2003).

Because the DCI relies on having ample creative ideas and innovation, including content and technology, its profit is created through ongoing content innovation; i.e., the creative companies' need to provide fresh content for catching the interest of the market. Taiwan's government has future policies related to this industry. It has declared that digital content will be the highest value-added and most competitive industry and has identified the DCI as the "star" that is full of potential for Taiwan. There are numerous fields within the DCI, and the niche for Taiwan is discussed in this study. The following topics are divided into four sections: the first topic, to be discussed in the next section, is the innovation and profit chain model; the third section, "Overview of the DCI" will analyze the DCI; the fourth section will discuss Taiwan's DCI's competitive posture in the global market; and the fifth section will conclude these discussions.

\section{Profit from Innovation in the Knowledge-Based Economy}

The characteristics of the knowledge-based economy are evolving technology, intensive knowledge-capital input, and continuous innovation. These factors are known to be the crux of industry. Contrasting with the ICT sector, the industry emphasis in a knowledge economy is not cost reduction or scale of economy. Content is the key factor which influences and causes the acceleration of content innovation.

\section{The Paradigm Shift of ICT}

Market domination through technology innovation is the goal for ICT sectors in either hardware or software. Manufacturing capacity is the measure for comparison within the ICT sector. The leaders, such as the United States, Scandinavian nations, and Japan, focus their expenditures on research and development (R\&D). In recent years, Organisation for Economic Co-operation and Development (OECD) has declared the forthcoming era as that of the knowledge-based economy, and the ICT sector will aim for knowledge capital instead of traditional production factors (OECD, 1996). The digital content industries aim at providing content and continuous innovation, but aim differently with $\mathrm{R} \& \mathrm{D}$ expenditures because of the importance of innovation (Griliches, 1990, 1998; Hausman, Hall, \& Griliches, 1984; Hitt, Hoskisson, \& Kim, 1997).

According to the British government's definition, DCI's consist of activities that have their origin in individual creativity, skill, and talent, which gives the potential for wealth and job creation through the generation and exploitation of intellectual 
property. These include the following key sectors: advertising, architecture, art and antiques, crafts, design, designer fashion, film, interactive leisure software, music, performing arts, publishing, software, television, and radio (DCMS, 1998; Drake, 2005).

The status of DCI development reflects the level of the knowledge economy and digitization. The production of DCI involves knowledge and innovation, which are intensive and aesthetic qualities (Drake, 2005). Hence it is not like other ICT sectors' mass production, pursued for cost leadership. DCI also aims at market orientation and customers' needs, which leads toward greater customization. There are many fields in DCI and each one has its own importance. Diversity and uniqueness are characteristics of this industry; hence there is a niche for small- to medium-sized countries, such as Taiwan, Korea, and Southeast Asian countries. Because DCI provides services and products formed from ideas and innovation, the profit model is different from other ICT-manufacturing value chains and will be discussed in the next paragraph.

\section{Service Value Profit Chain}

Heskett (Heskett, Sasser, \& Schlesinger, 1997) declared that enterprises need to focus on providing stakeholders, such as their employees, customers, investors, suppliers, and others, the greatest value. Focusing on this value will require necessary changes for enterprises. Tying an enterprise to customer needs will make it more responsive to its markets. In addition, giving employees attractive benefits in an enterprise will make them more productive and decrease the costs of employee turnover. The result is a value approach that will result greater effectiveness and profitability.

In the service industry, internal quality management influences the operating performance of services and products, which closely links to client loyalty. To keep market share, enterprises have to offer predictable services or products. DCI needs to have continuous innovation for advancing the quality of their products or services. For example, within the animation area, a good, attractive animation product would strengthen the relationship between customers and employees. Greater customer trust and loyalty creates increased profits, which makes the enterprise more attractive to new investors and expands the market further.

As Figure 1 shows, the service-profit chain emphasizes the internal value which includes the capabilities and distinctive technology resulting in high quality services

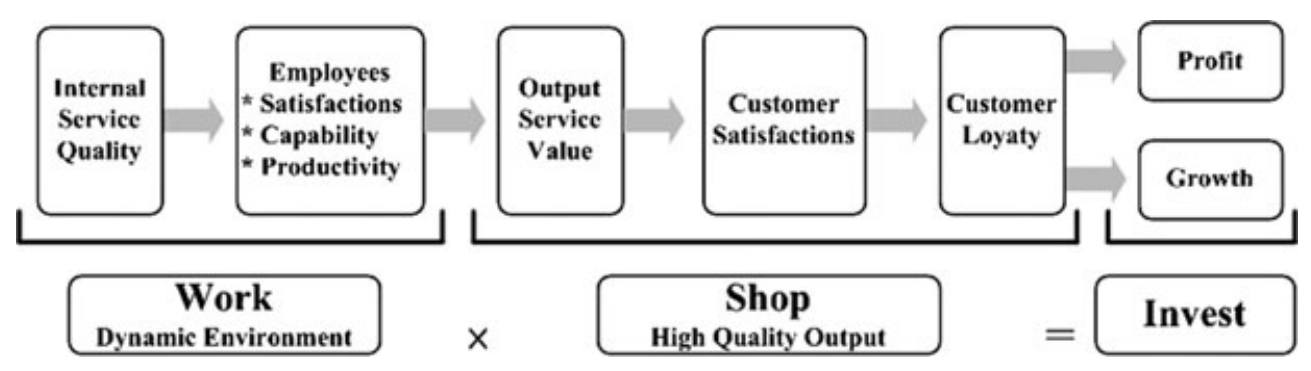

Figure 1. Value Profit Chain of Service Industry

Source: Heskett and others (1997); modified by author. 
for satisfying the customers' needs. Increasing the added value of services/products increases the value of output services and keeps customer satisfaction and loyalty high.

\section{Profit Chain of Innovation}

Innovation can be described as providing new services and products through the use of new knowledge, which includes invention and commercialization in creative industries (Afuah, 1998). The crux of innovation lies in the accelerating speed of knowledge that is being created and accumulated (OECD, 2004). A related characteristic of knowledge economy growth that has become increasingly evident from the early twentieth century and onward is the growing importance of intangible capital (also called intellectual capital). In total productive wealth and at macroeconomic levels, the rising relative share of GDP is attributed to intangible capital (Abramovitz \& David, 2000). For DCI, intangible capital basically falls into two main categories: (1) services for digitalized content, such as movies, mobile services, and radio, and (2) added-valued application products, such as digital archives, publications, and ebooks.

The profit of the DCI mainly comes from intangible capital, which is different from ICT goods that are priced by the market. The value of ideas is subjective and differs greatly with the production orientation strategy. Corporations that offer more innovative products, services, or diversified goods have the potential for earning higher profits. According to the profit chain offered by Afuah (Afuah, 1998), knowledge (idea initiative) is the main key success factor (KSF) that corporations rely on. Knowledge represents the "distinctive competence" and "capability" which can satisfy market needs and can differentiate a corporation from its competitors. As noted earlier, the environment of the DCI is highly dynamic, hostile, and has low heterogeneity. This is incorporated in the profit chain of this industry, as shown in Figure 2.

Through the dynamic environment of innovation, unique and creative ideas are transferred into valuable and practical knowledge for developing products. Gaining higher profits and market share are common industry goals, and if integrated with the concepts of the value-profit chain mentioned earlier, it can be modeled in three

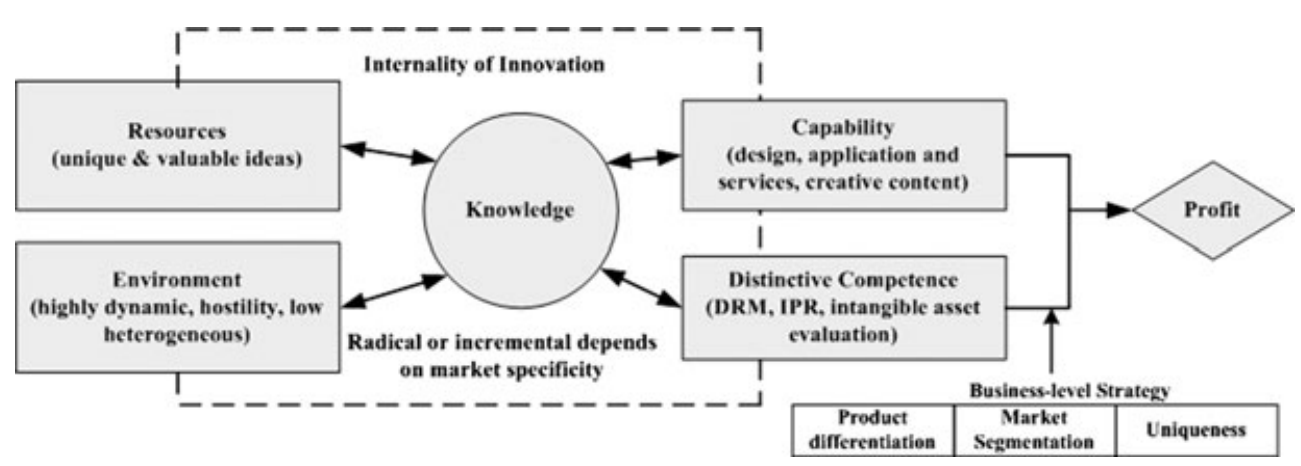

Figure 2. Profit-Chain of Innovation in Digital Content Industry Source: Afuah (1998); modified by author. 


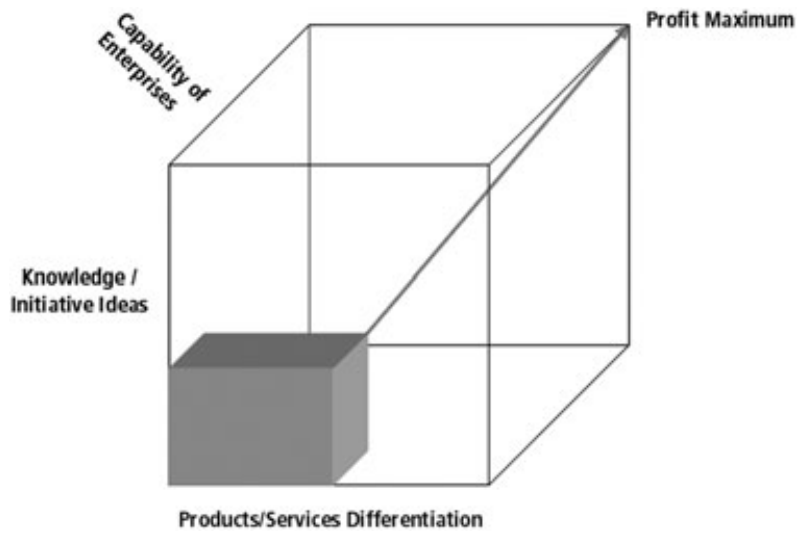

Figure 3. Profit Potential in Digital Content Industry

dimensions by each driving factor. For reaching the profit maximum, the capability of enterprises, cycle of employees in service-profit chain (which is aforementioned in the previous section), and knowledge/initiative ideas are the sources of distinctive competence within adapting the differentiation strategy (see Figure 3).

\section{Overview of the DCI}

Uniqueness and initiative capability are emphasized in DCI, and the scale of production is not the main issue. Success in this industry is determined by the acceptance of a company's products by the market; hence, small- to medium-sized countries like Taiwan, Singapore, Hong Kong, New Zealand, and Korea can more easily establish competitive advantages in this area. As Scott and Storper (2003) observe, "There is mounting evidence that creativity and learning have a distinctive geography, with regions playing active roles as sites of continuous and informal but cumulatively significant improvement in industrial products and processes." The DCIs have all the characteristics of high-tech industries and require a welldeveloped ICT infrastructure to serve their clientele and interaction with an IT manufacturing base to create and target their products. Creative subsectors, such as the process of movie making and electronic games, depend on local and international networking in order to develop successful commercial products that enhance their market prospects. The nature of such local networking is presented in Figure 4 .

\section{Definition and Market Scale of the DCI}

Being highly export-oriented and dependent on personal contacts with buyers, reliance of the DCI on networking is greater than for manufacturing firms (Yusuf $\&$ Nabeshima, 2005). Cultural-products industrial enterprises around the world are becoming increasingly connected with one another in global webs of coproductions, joint ventures, creative partnerships, and so on. In this manner, productive combinations can be established and can draw on the specific competitive advantages of diverse clusters without compromising the underlying force of enterprise itself (Scott, 2003). 


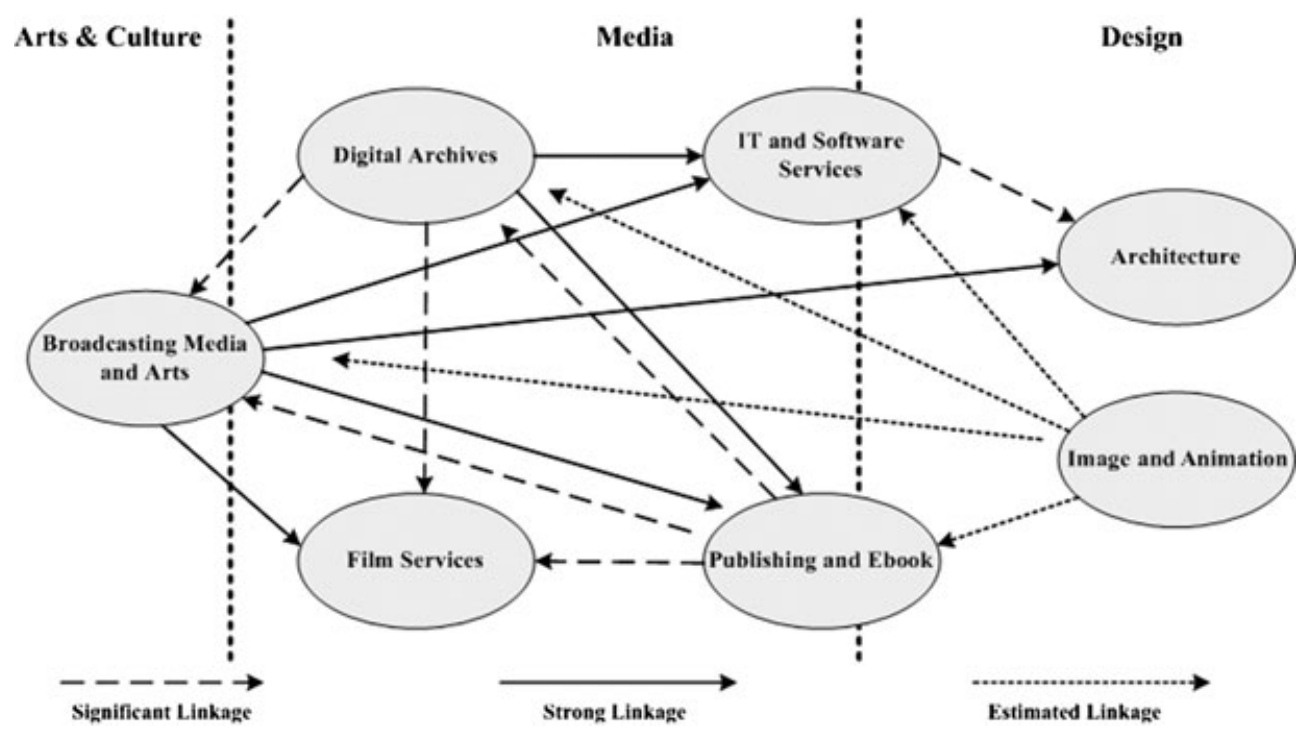

Figure 4. Networking Among Creative Industries

Source: Yusuf and Nabeshima (2005); modified by author.

Definition of the DCI-Most creative industries can also be called DCIs because their products are made through digitalization. A recent European study defines the DCI as "including net-business which delivers digitized information (text, data, image, audio, and video)." The core of the DCI can be identified as the converged traditional media sector, e-publishing, and digital audio visual industries. While the traditional media sector produces digitized text, data, and images, the other DCIs focus on digitized television, voice, and video sequences (Allen Consulting Group, 2003).

Scale of the Digital Content Market-The creative economy and the digital content markets are closely connected. DCI could be defined by creative economic activities. Most of the activities that are identified in the creative economy use digital inputs or produce digital goods and services to a greater or lesser extent. The least digital activity in the list is most likely crafts. Activities, such as software and video games, are now almost universally digital, while the transacted part of activities, such as music, are becoming heavily digitized. CDs and DVDs now dominate music, although there are still significant sales of vinyl records, which are considered analog forms. The challenge is in determining what proportions of digital content activities have been digitized.

According to the statistics mentioned in Figure 5, the scale of the DCI market has reached US $\$ 1.13$ trillion and will continue to grow to US $\$ 1.18$ trillion in 2004 . The semiconductor industries are only at US $\$ 0.215$ trillion, or 18 percent of the size of the DCIs. Figures 5 and 6 are predictions of DCIs in the global market. One noticeable point is that DCIs in Asian countries are growing rapidly, and the figure shows that these small- to medium-size countries build their own advantages for competing in globalization. 
Production Value (unit: million dollars)

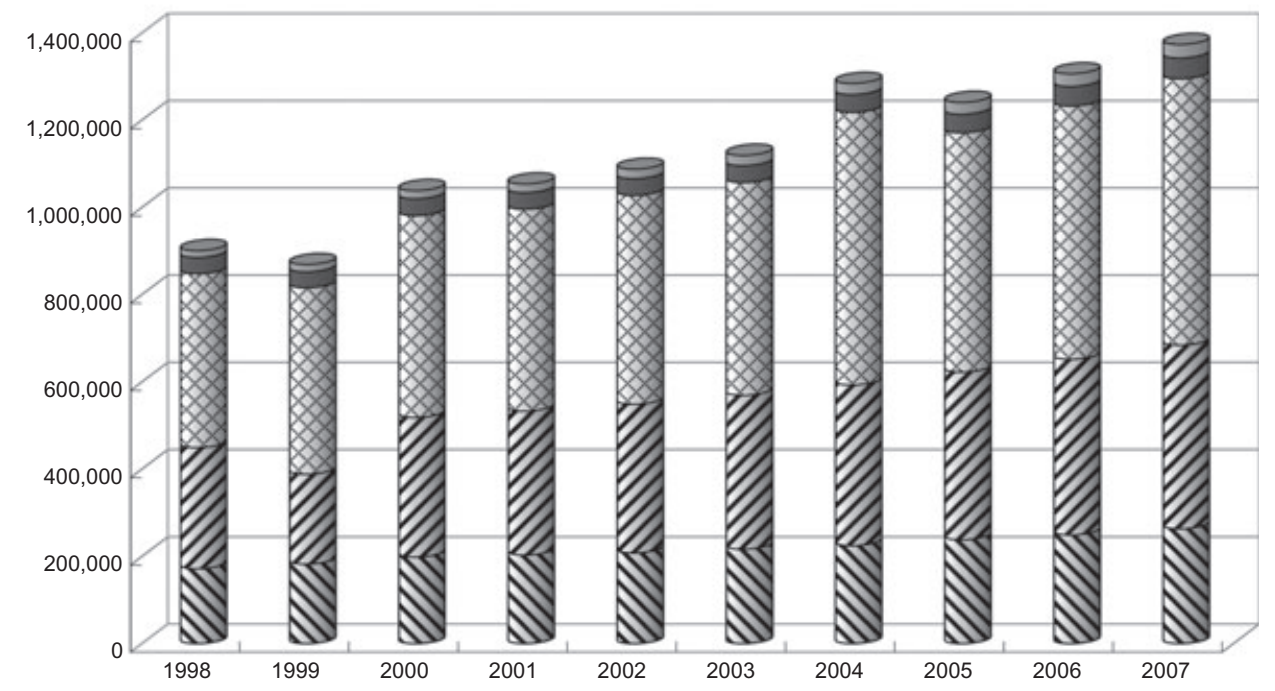

$\triangle$ Asia Pacific \EU $\square$ U.S. $\square$ Latin Africa $\square$ Canada

Figure 5. Forecasting the Scale of Digital Content Industries in Global Markets Source: PriceWaterhouseCoopers (2004).

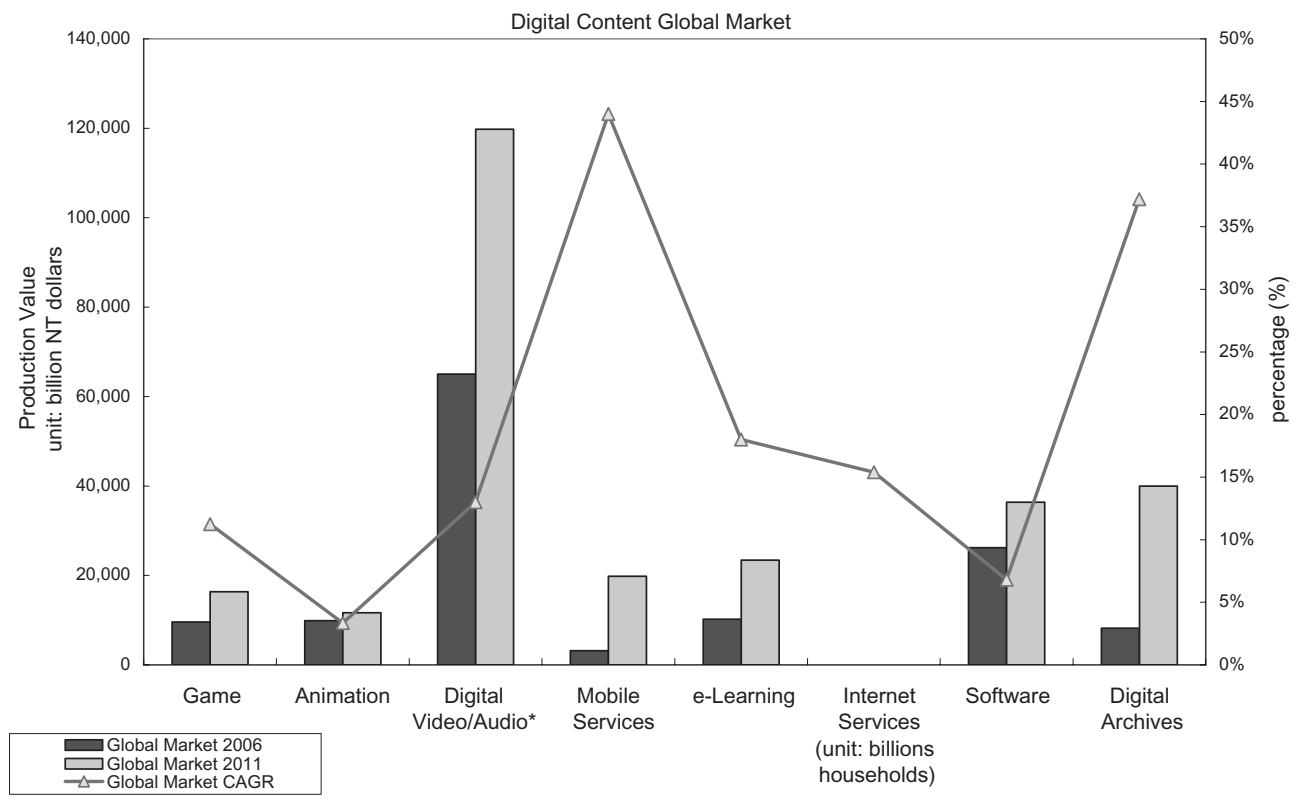

Figure 6. Forecasting the Scale of Digital Content Industries in Each Category Source: Ministry of Economic Affairs (2004).

\section{Value Chain of $\mathrm{DCls}$}

Digital content assists creative processes throughout the economy because it accelerates the spread of ideas. Digital content makes ideas, knowledge, and information easier to store, distribute, and access. As mentioned earlier, the investments for DCI 


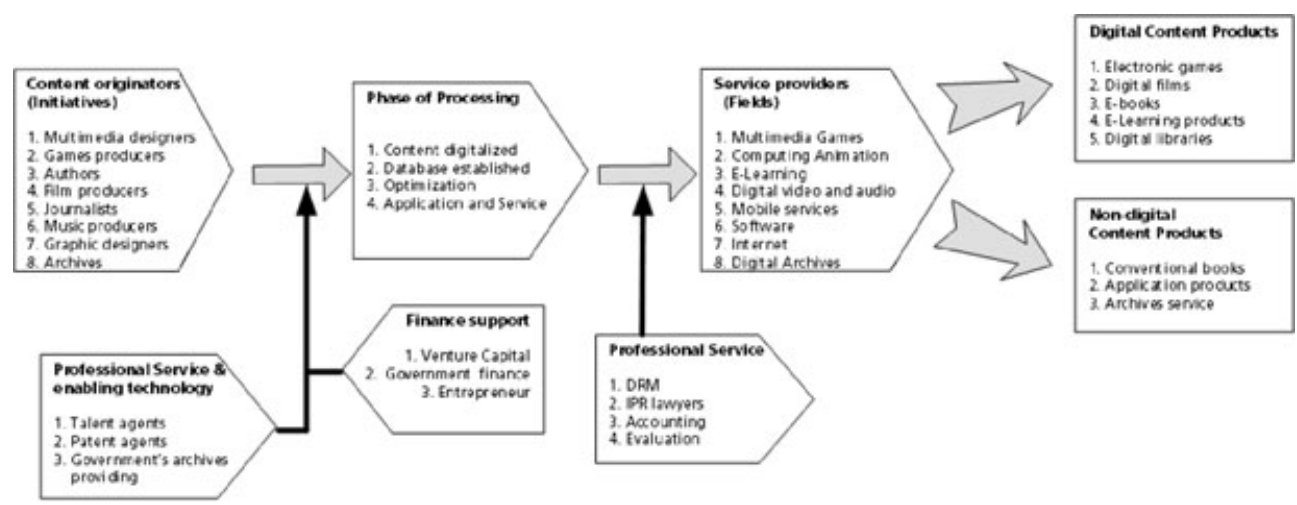

Figure 7. Value Chain of Digital Content Industry

Source: Scottish Enterprise (1999); modified by author.

are mostly intangible/intellectual capital, plus substantial financial support. Venture capital in the ICT sector has existed for many years, but it is still in its initial stages for DCI. ICT sectors pursue cost leadership and meeting market demands, therefore, the investment in ICT manufacturing produces profits quickly from the market. However, DCI is different from ICT sectors because the products of this industry are unique, diverse, high value added, and not mass produced. The most important consideration for the DCI is that idea initiatives must emphasize quality and market acceptance.

The profit chain of DCI, in contrast with ICT manufacturing, is "value innovation" that focuses on content. In Figure 7, the profit chain of DCI is shown.

\section{Taiwan DCI Status}

The DCI in Taiwan includes videos, games, publishers, and e-learning that can be divided into core and staff. Core industries use applications, such as video and audio, computing animation, multimedia games, e-learning, mobile services, and digital archives, where staff industries include content software and Internet services (Yusuf \& Nabeshima, 2005). The production value of Taiwan's DCI in 2006 reached NT\$3,412 billion and the average annual growth rate was 22 percent.

According to the statistics from Ministry of Economic Affairs (MOEA), the number of companies in DCI is approximately 1,600 and is expected to grow to over 3,000. There are about 33,000 employers, which will most likely expand to about 40,000 , thereby offering more job opportunities. In applications and services, the DCI export ratio in production value is 12 percent today and DCI companies predict that this number will continue to grow to 30 percent.

\section{The Government's Policy for Development}

e-Infrastructure: Bandwidth First, Content Later-The E-Taiwan Plan is to improve its competitive position through the infrastructure of electronics (e-Infrastructure). The government needs to build up sufficient bandwidth for attracting users, and this is the first step toward increased market penetration. The Taiwan government 


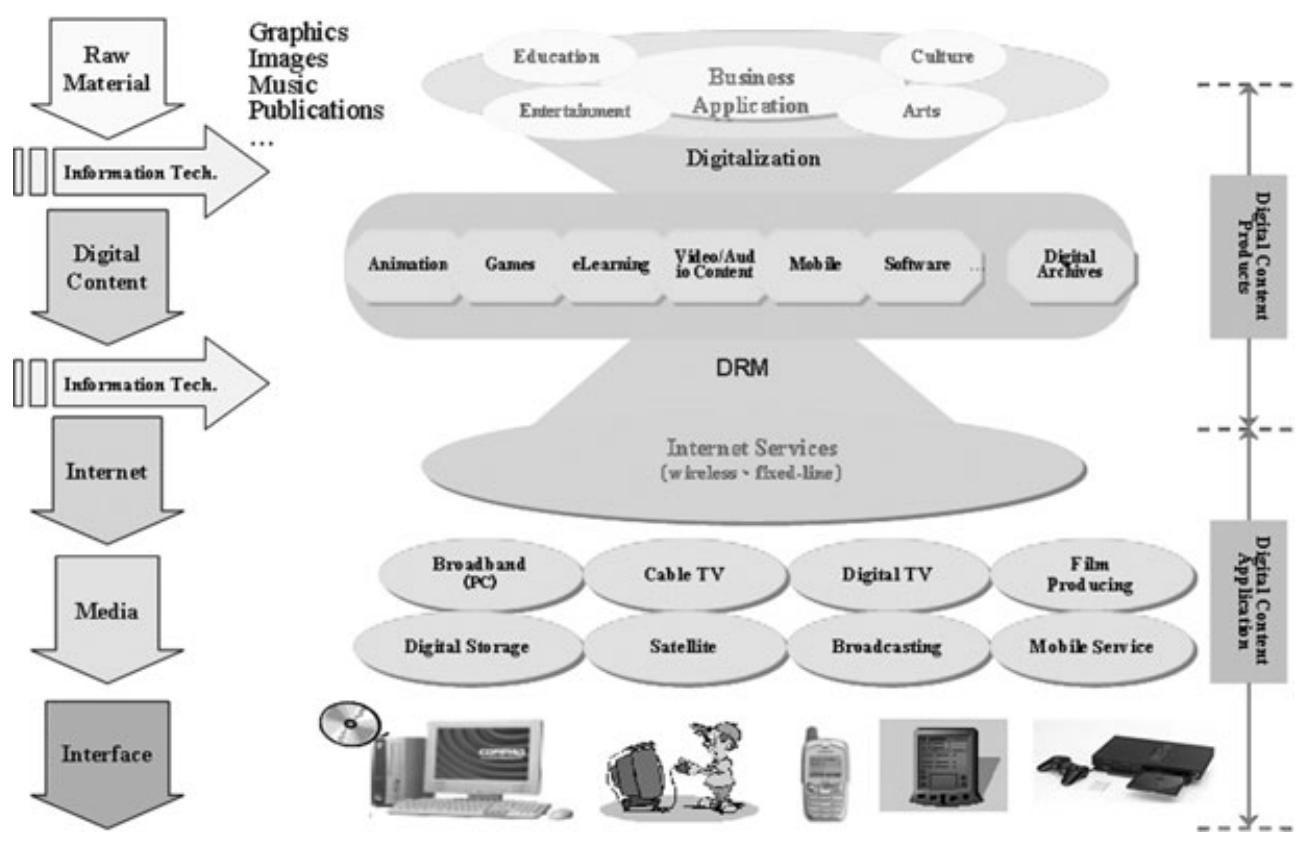

Figure 8. The Promotion Strategy of Taiwan's Policy for DCI

Source: Scottish Enterprise (1999); modified by author.

plans to invest about NT $\$ 360$ billion in Taiwan digitalization, of which 80 percent would be for private companies. It expects to increase investment to about NT $\$ 1,000$ billion production value in informatics and 20,000 opportunities for employees (MOEA, 2004).

There is a close relationship between the development of digital content and e-infrastructure. An environment with sufficient bandwidth helps the development of various types of digital content and builds a platform for suppliers and users. More access would create information pluralism and would spur more creative ideas for satisfying user and customer needs. Taiwan's penetration of broadband is twelfth in the global market and its position is continuing to increase. When complete, the e-infrastructure will help provide an incubator for creativity.

Taiwan Digital Content Incubation Policy-Following the trends of the knowledge economy to build the "Digital Content Design Center of Asia," Taiwan's MOEA promotes the policy of a strong creative economy for enhancing the country's competitive position. Taiwan's government has declared that DCIs are one of the "Two Trillion and Twin Star Industries" and has started to pursue policies and bills related to the environment, human capital, financial support, R\&D, global marketing, and applications that will support DCI. Taiwan's strategy is illustrated in Figure 8 .

The government is providing support in five areas. First of all, the Digital Content Industries Promotion and Development Office has been establishing policies and strengthening cooperation between industries and academic institutes. Second, the government has created the Digital Content Institute for cooperation between industries and universities to develop human resources in this field. Third, 
it promotes the "Center for Evaluation of Digital Content and Investment Services." The value of digital content has yet to become efficiently priced in the market, so the evaluation center will offer objective pricing services for all intangible assets. The fourth area includes offering loans or financial support. Last but not least, it is providing national archives, including pictures, art, historian source material, metadata and other materials to companies for value-added applications, such as worthy Chinese drawings that are applied on decorations, handkerchiefs, tableware, or dishware. These drawings are very popular and are highly accepted in the international market (MOEA, 2005).

In a global market, government policy has to be effective to create value for firms. DCI will need to capitalize on existing opportunities that are likely to emerge, but also contribute to the future dynamics of these companies. The major questions cities face that seek to strengthen innovative capacity are: what kind of models can they use as points of reference, what kind of measures can they take to enhance attraction of new firms, and, particularly, how can they create clusters of industries and services that can accelerate an industry's growth.

Governments play an important role in DCI because the industries are highly changeable and require intensive capital investments, such as required for producing film or music or establishing databases. These are not possible for just a few companies to handle on their own. In the early stage of industry development, governments need to establish mechanisms for assisting DCI, such as policy guidance, financial support, enabling technology imports or transfers, and community formation. DCIs need large amounts of capital investment and a long time horizon for investment return. According to the locus of industry leadership, the following approach can be used to define DCI strategies, which are broken down into three levels: national, industry, and firm. Comparison between Taiwan and other countries' policies is helpful for understanding the differences in strategy. The locus of industry leadership and international policies are explained in Tables 1 and 2.

The Taiwan government's DCI policy is divided into six main parts and 27 issues. The policy framework is constructed based on the specific technology for which it is setting rules. Taiwan's DCI policy tries to be well-rounded and invests large amounts of money for aiding the industry development. However, according to the locus of industry leadership, DCIs are in a dynamic situation and are still immature;

Table 1. Locus of Industry Leadership in the Digital Content Industry (DCI)

\begin{tabular}{|c|c|c|c|}
\hline & National Level & Industry Level & Firm Level \\
\hline DCIs & $\begin{array}{l}\text { 1. DCIs belong to long-creation } \\
\text { industry, but have short life } \\
\text { cycles. } \\
\text { 2. DCIs need intensive capital } \\
\text { investment and the nation's } \\
\text { resources are the most } \\
\text { important factors. } \\
\text { 3. Small- and medium-sized } \\
\text { countries could enter the } \\
\text { market by the use of unique } \\
\text { products. } \\
\text { 4. Intellectual property laws } \\
\text { protection. }\end{array}$ & $\begin{array}{l}\text { 1. The link between industry and } \\
\text { academic institution should be } \\
\text { established as soon as possible. } \\
\text { 2. The formation of DCIs value } \\
\text { chain will be another key } \\
\text { success factor. }\end{array}$ & $\begin{array}{l}\text { 1. DCIs are in low heterogeneous } \\
\text { environment and choose one } \\
\text { segment to enter. } \\
\text { 2. Intangible assets do not } \\
\text { necessarily have product life } \\
\text { cycle, so the diversified } \\
\text { product is an important } \\
\text { strategy. }\end{array}$ \\
\hline
\end{tabular}


Table 2. International Digital Content Policies

\begin{tabular}{|c|c|c|c|c|c|}
\hline & Canada & Korea & Japan & U.K. & Taiwan \\
\hline Public office & $\mathrm{CH}$ & MCT \& MIC & MITI & DTI & MOEA \\
\hline $\begin{array}{l}\text { Promotion } \\
\text { institution }\end{array}$ & $\begin{array}{l}\text { Telefilm Canada } \\
\text { NFB }\end{array}$ & $\begin{array}{l}\text { KCIPC } \\
\text { KIPA } \\
\text { KGDI }\end{array}$ & DCAJ & DCF & DCPDO \\
\hline Emphasis & $\begin{array}{l}\text { TV, film, new } \\
\text { media }\end{array}$ & $\begin{array}{l}\text { Games, cultural } \\
\text { content, digital } \\
\text { content }\end{array}$ & $\begin{array}{l}\text { Games, software, } \\
\text { film, music, } \\
\text { publications, } \\
\text { services }\end{array}$ & $\begin{array}{l}\mathrm{TV} \text {, film, } \\
\text { publications }\end{array}$ & $\begin{array}{l}\text { Games, animation, } \\
\text { video/audio, } \\
\text { Internet service, } \\
\text { digital archives, } \\
\text { software }\end{array}$ \\
\hline
\end{tabular}

Source: Ministry of Economic Affairs (2004).

hence, DCIs are not like other ICT products and should follow a standard, which fulfills applications of technology. The industry needs extensive capital to be able to pioneer new ventures into the market. The DCI market has both "clear market segmentation" and "distinctive competence," which are becoming the two most important factors for producing unique content. When becoming the first country to move into a market, Taiwan's policy strategies are to invest in technology exploitation, creative human resources, and global market promotion. Not only do related policies subsidize new start-up DCI companies, but also encourage cooperation between industries and academies, like the "Technology Development Program in Academia," and the "Industry-Academia Corporation Platform."

\section{Challenges for Digital Content Policy}

1. Financial support. The Bureau of Industry has formed an institute for intangible evaluation and venture services. The government offers NT $\$ 200$ billion for loans beginning in 2004 to incubate NTBFs of DCI. In regard to other financial support, venture capital in Taiwan differs from the United States and many European countries. These countries positively encourage new start-up companies and even favor the relatively less stable companies over other stronger firms. Most DCI or cultural creative companies fall in the range of small- to medium-size and have limited funds for R\&D and innovation. In this situation, DCI needs to be considered at the national level, where the government provides financial support for these creative companies. The strategies of MOEA in Taiwan are to provide government funding support, which includes tax incentives, loan support, introducing foreign investment, and interindustrial alliances. They also wish to improve the constantly growing industries.

2. Human resources incubation. Limited by the regulation of industry and education, an efficient linkage between academics and industries has not yet developed. The government has built science parks to attract NTBFs and has founded an institute for training in the necessary skills; however, problems still occur as market needs are not satisfied and the skilled professionals are not sufficient to support industry.

Today there are many countries, including the United States, the UK, Japan, East Asia, Australia, and India that are actively developing and promoting DCI 
because it can help to "push and pull" on other industries' growth, especially the more traditional ones and the ICT sectors. One of the reasons is digitalization needs other industries' innovative technology to work efficiently; however, there are many fields in DCI that are dependent on limited resources. Governments should seek a proper strategy to develop the most competitive industries. A good example of this technique is the United States, which helps fund the film industry's production technology, market, channel, and ideas. This is an advantage that other countries have a difficult time competing with, especially small- and medium-sized countries, like Taiwan, Singapore, and Korea. In Innovative Intense Services (IIS), dominating a sector makes it very difficult for small countries to compete.

\section{Focus on Taiwan's Niche}

In Table 2 in the preceding section, it is clearly shown that countries emphasize the development of DCI in their own areas of strength, or vantage points, because of the limited available resources. It is hard to cover all fields, and the enabling technology is the key factor for determining what industry-development areas to focus on. The enabling technology can be divided into two parts: one is what the technology industry uses, such as applied software, video/audio technology, and digitalized technology; the second is interface technology, such as hardware, telecommunications, and internet infrastructure. The Korean policy states the government plans to invest about Kor $\$ 6,100$ million on a multimedia technologysupport center. The center's purpose is to develop virtual reality and computer graphics technology to improve online game quality, and thereby attracting more players. The UK focuses on publications and media because they have a large amount of archives and a flourishing media industry. These are good foundations for developing DCI. These policy decisions show that in DCI, even for technology leaders like the United States, it is hard to achieve an all-inclusive development program. Each country has to put their limited resources into the most efficient items to bring in the greatest amount of profit.

The theory of locus in industry leadership clearly defines the DCI position and situation. Similar to the development of tech and biochips, this industry is still in the process of growing and still contains many risks. One question is: can the development of technology keep up with industry's growth? DCPDO (Digital Content Promotion and Development Office) has investigated and analyzed Taiwan's environment and policy for developing DCI. Based on the experts' and companies' opinions, they presented a report about the KSFs of Taiwan's DCI. In this study, the report describes the status of the global market. The experts' opinions and analysis of the risks of these factors are shown in the following Table 3. In this study, it assumes that there are numerous variables for analyzing the KSFs. High risk is defined as highly dynamic and hostile, and indicates that it is not the right time to develop this issue in Taiwan. Low risk is more appropriate for Taiwan's status quo and can gradually be developed. The vantage point indicates that the critical factors exist for having the ability to easily influence the developments of industry.

From the analysis in Table 3, the whole DCI environment has high risk in Taiwan. The government should choose the profitable fields to invest in, following examples of Korea's emphasis on Internet services and online gaming enhance- 
Table 3. The Analysis of DCI's Key Success Factors (KSFs) in Taiwan

\begin{tabular}{|c|c|c|c|c|}
\hline Issues & KSFs & High Risk & Low Risk & Vantage Point \\
\hline \multirow{3}{*}{$\begin{array}{l}\text { Digital video/audio } \\
\text { application }\end{array}$} & 1. Established fixed users & $\checkmark$ & & \\
\hline & 2. Killer application software & $\checkmark$ & & $\checkmark$ \\
\hline & 3. Human resource incubating & & $\checkmark$ & \\
\hline \multirow{2}{*}{ Games } & 1. Encourage new start-ups & $\checkmark$ & & \\
\hline & 2. has to be creative content & $\checkmark$ & & $\checkmark$ \\
\hline \multirow[t]{2}{*}{ Animation } & 1. Technology development & & $\checkmark$ & \\
\hline & 2. Creative ideas and topic & $\checkmark$ & & $\checkmark$ \\
\hline \multirow[t]{2}{*}{ e-Learning } & 1. Useful content and easy use & & $\checkmark$ & \\
\hline & 2. Should expand the application target & & $\checkmark$ & \\
\hline \multirow[t]{2}{*}{ Mobile service } & 1. Broadband infrastructure & & $\checkmark$ & $\checkmark$ \\
\hline & 2. Content and service renewal & $\checkmark$ & & $\checkmark$ \\
\hline \multirow[t]{3}{*}{ Software } & 1. Incubating human resource & $\checkmark$ & & $\checkmark$ \\
\hline & 2. Corporations with foreign software producers & $\checkmark$ & & \\
\hline & 3. Key and most users software exploit & $\checkmark$ & & $\checkmark$ \\
\hline \multirow[t]{2}{*}{ Internet service } & 1. Well-done infrastructure (high speed and capacity) & & $\checkmark$ & $\checkmark$ \\
\hline & 2. Mature user community & $\checkmark$ & & \\
\hline \multirow[t]{4}{*}{ Digital archives } & 1. Rich raw archives or materials & & $\checkmark$ & $\checkmark$ \\
\hline & 2. Application and services promotion & & $\checkmark$ & \\
\hline & 3. Global marketing strategy & $\checkmark$ & & \\
\hline & 4. Continuous content innovation & $\checkmark$ & & $\checkmark$ \\
\hline \multirow[t]{3}{*}{ Financial support } & 1. Government policy support & & $\checkmark$ & $\checkmark$ \\
\hline & 2. Loan incentives & & $\checkmark$ & $\checkmark$ \\
\hline & 3. Value chain & $\checkmark$ & & $\checkmark$ \\
\hline
\end{tabular}

Source: Digital Content Promotion and Development Office (2005); modified by author.

ment. Insufficient and divergent resource allocations are the cause of inadequate industry development and can also postpone the time for products to enter the market. In fact, DCI is a demand-side market and requires the acceptance of users that would value the ideas. Some fields, such as digital video/audio, digital games, software, and Internet services, are almost all high risk. These fields need a constant flow of fresh ideas; otherwise, it will be difficult to achieve high added value. Moreover, broad market size is necessary to ensure the survival of DCI; however, Taiwan's domestic markets are limited. One solution is to develop the export market. Also, human resource development and management will require a large investment. Therefore, Taiwan's government should consider these issues when making policy decisions. In this study, the strengths, weaknesses, opportunities, and threats (SWOT) analysis of DCI from the research of KSFs is shown in Table 4.

From the SWOT analysis, it can be concluded that Taiwan's obvious advantages in DCI are the "market" and "linguistic familiarity" in China. The Chinese market has a high acceptance rate for new innovative commodities. In addition, the 2008 Olympic Games is approaching in Beijing, so national pride has been rising and both the Chinese and foreigners are enthusiastic about Eastern culture. Therefore, it will be a good opportunity to promote Taiwan's DCI capabilities in different fields. DCI needs creative human resources or talent agents, and the most important factor is creating an environment where aesthetics and creativity will prosper and will result in innovation. DCI is like "artifacts imbued with imaginative aesthetic and semiotic content." (Scott, 2000) Although there are some Taiwan universities or institutions doing arts, the relationship between arts and industries is seldom built on, causing a shortage of creative talent supply as a source of innovation. The limitation of domestic market size and lack of emphasis on the demand side of the market are also problems DCIs have encountered. DCI products are high value 


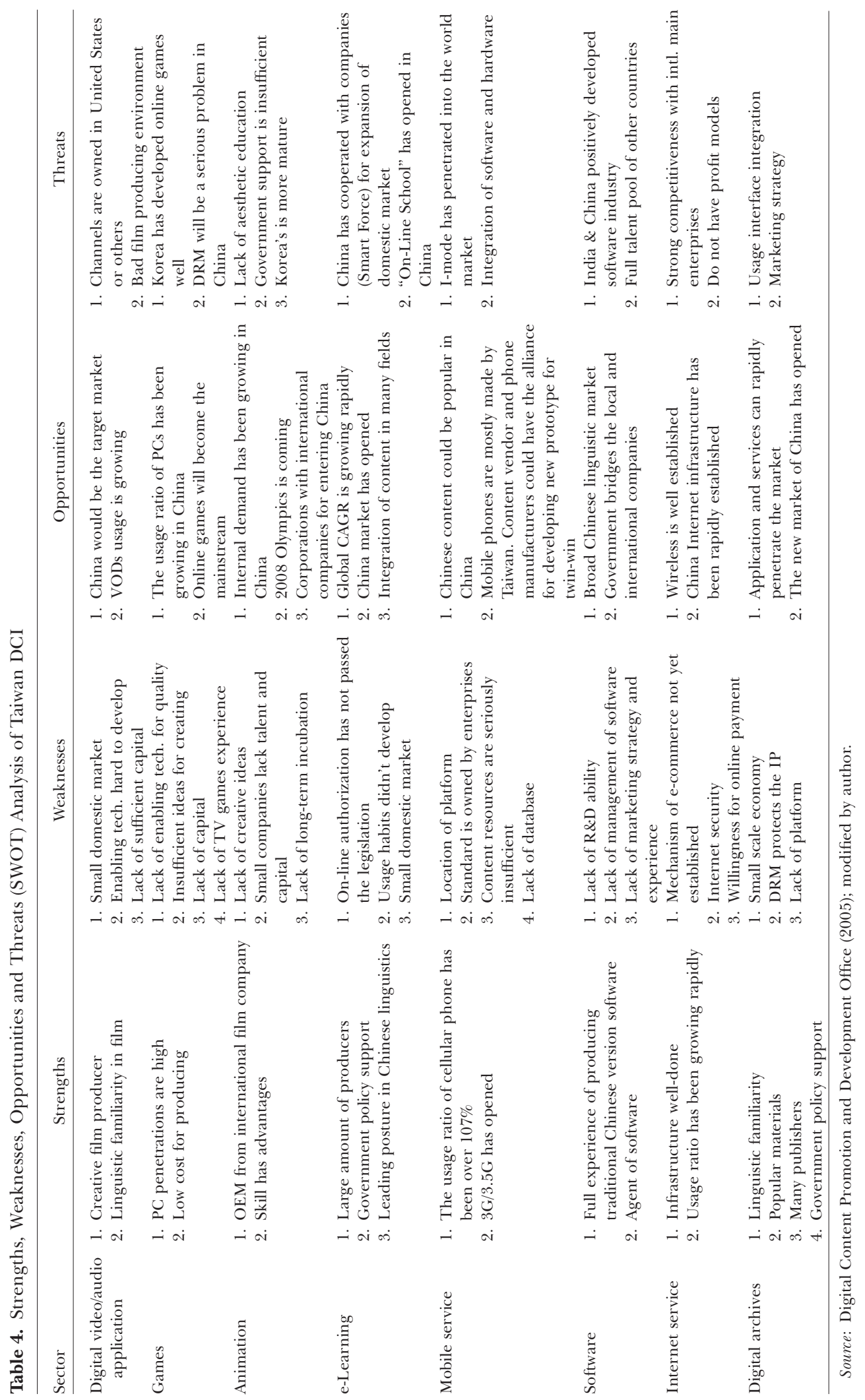




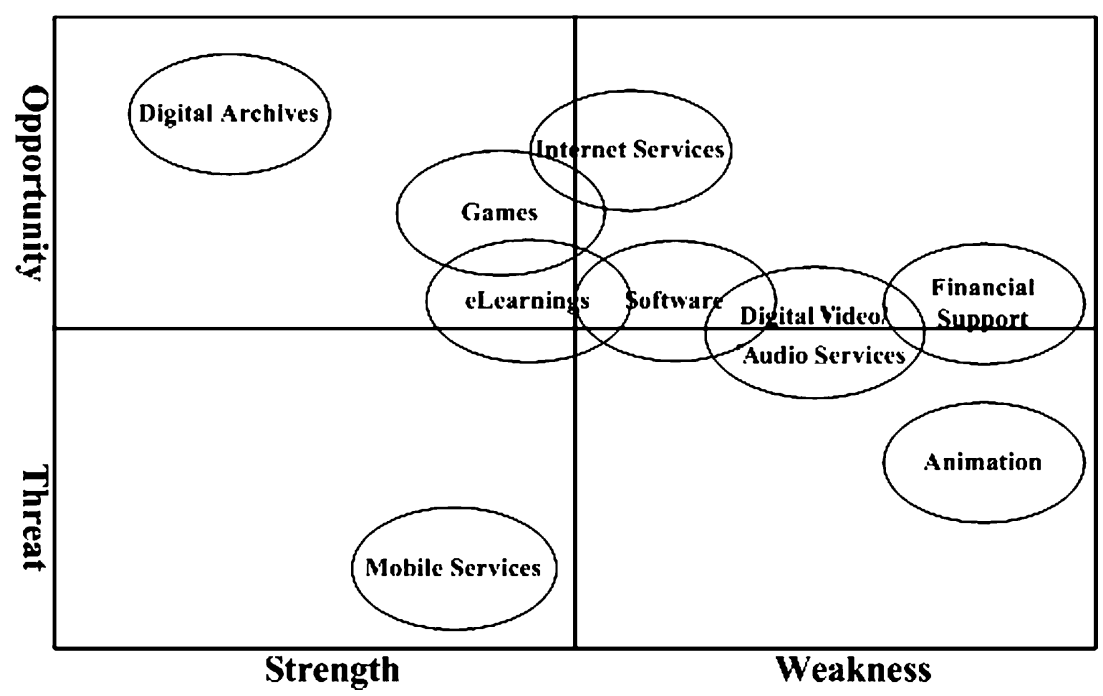

Figure 9. Strengths, Weaknesses, Opportunities, and Threats Matrix of Taiwan Digital Content Industries

added when compared to ICTs, but the demand side of the domestic market is limited by the market scale and cannot be expanded. Thus, global marketing strategies and government support are needed. Lastly, the government should have a strategy that focuses on the most profitable sectors, because each area of DCI needs significant capital investments.

Figure 9 is developed from the SWOT analysis and shows that Taiwan still has the potential to develop certain fields. The matrix analysis of Figure 10 shows the "production value" and "CAGR" for the different fields. From both analyses, it is clearly demonstrated that "e-Learning," "digital archives," "games," and "mobile services" are in strong positions in this industry and have CAGRs above average. This position can be seen as the "potential field," which has high growth rates and taking-off production value, also corresponding with the global market status. Other sectors are not in high CAGR; however, their CAGR still reflects opportunity in global market. Lastly, some fields reflect limited opportunity in the global market, such as animation that has low CAGR and production value.

These analyses clearly show advantages and disadvantages for Taiwan's DCI in the various sectors. They also indicate which areas will be more advantageous for Taiwan to develop, such as "digital archives," "e-Learning," and "mobile services," which are more attractive than other sectors because of their low risk and available materials for doing applications and services.

\section{Discussion: High-Growth Potential Groups}

The development of broadband wireless access (BWA) and related infrastructure, including backbone and bandwidth, plus BWA devices and applications, offer users numerous high-quality services. The phrase "Content is the king" declares the importance of content in the interrelationship between content and equipment.

Because portable BWA devices, such as mobile phones, PDAs, smartphones, and NDPs, will likely become the most used connections to the Internet, content 


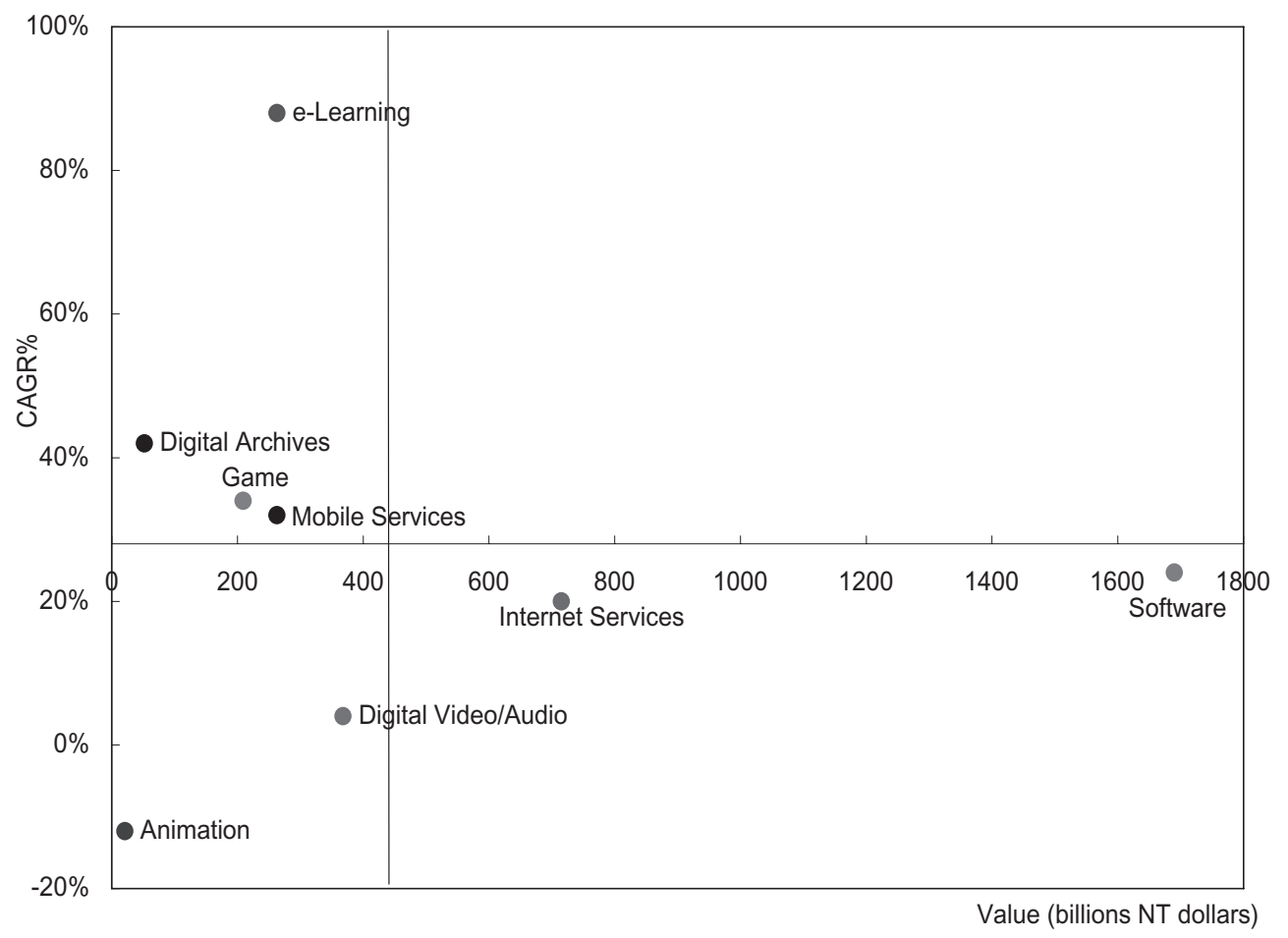

Figure 10. Matrix Analysis of Taiwan Digital Content Industries by CAGR and Production Value

installed in these devices will dominate the user's choice. Mobile services, such as NTT DoCoMo's successful I-mode, have entered a highly competitive environment. Taiwan mobile service providers actively design and develop new services and have had good success. Furthermore, they should have additional opportunities with the upcoming Olympics in Beijing. Familiar linguistic advantages and interfaces will provide a good business opportunity for these companies.

e-Learing in Taiwan exists in internal training for enterprises and educational usage such as cram schools or institutions. Consulting companies are gradually developing software offerings to enterprises that do Web training. China is a new emerging market for foreign or domestic enterprises and they need skilled staff. Taiwan vendors should develop or design the packages for them by using their substantial experience and capability. In educational uses, some institutions have tried to develop software or interfaces for students (no age limitation) but without good results. However, the experience and materials have helped develop good fundamentals.

With China opening their market to the world, the Chinese will become the largest group of Internet users, and the content indicates the Chinese will help the market to grow at twice the speed. DCIs have cultural compatibility and uniqueness, so the vantage point for Taiwan's DCI development is to become the pioneers of China's digital content market. Globalization is forcing China to enter the information technology era. Meanwhile, the infrastructure and technology are rapidly growing and the ratio of users of information technology is becoming much higher. These are factors and conditions that cause foreign companies to positively invest 
capital and human resources. For example, Hong Kong has a key position in globalization and is at the confluence of different cultures that will give it the opportunity to lead DCI into the market. Taiwan also has this advantage as it relates to China. Therefore, Taiwan has the potential and opportunity to gain share in China's market and eventually enter the global market.

Taiwan could be seen as the channel of Chinese digital content, and the cultural similarities can help Taiwan DCI companies do vertical integration more easily. Clearly, Taiwan's government should help the DCI to build up a global marketing strategy system and create sufficient financial support.

After analyzing DCI opportunities, more efficient resource utilization for digital archive applications and services should be the first priority in policy making. Digital archives are just one part of DCI, but it offers an important database toward the whole DCI development. Applications and services will become high valueadded areas and will expand to other sectors by offering new ideas and creativity. Traditional archives' application and services are similar to replicas of famous paintings or works of art. Digitalization will rapidly increase the value of these archives, such as printing the symbol or signs of Chinese paintings onto wallpapers, cards, counterpanes, or other decorations. People may be attracted by these products' design and creativity and may be willing to pay more for them. If so, the added value will be increased. The goal of digital archives is to prevail and spread the exquisite cultural applications. The arts have their uniqueness, so the market segmentation will be obvious and the companies can segment prices and differentiate products in order to dominate the market. For the overall effect, digital archives will have influences on two dimensions. The first is in human and social sciences (Hsiang, Chen, \& Cheng, 2002). Through digital archive applications, aesthetics will be combined with the technology for education and help "mold the palate" for spurring new ideas and innovation. The second dimension is in industry and the economy. Digital archives can transfer cultural heritage into valuable information and commodities and would accommodate digital databases in animation development, software, or film production.

Today, the composition of Taiwan's DCI is mostly made up of small- to mediumsized enterprises lacking industry leadership. Although SMEs are flexible in developing their own unique products, they have difficulty facing the challenges from international companies. Consequently, the government should assist digital archive companies by establishing a transaction platform for archives accessed for added-value products and then distributed to the channels (see Figure 11).

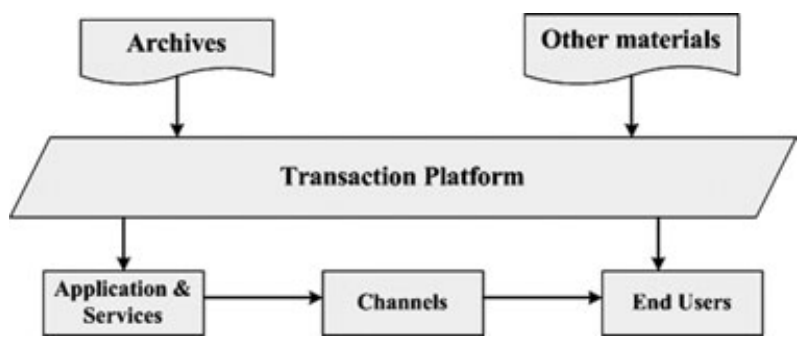

Figure 11. Transaction Platform of Digital Archives 


\section{Conclusion}

This research shows the potential fields for DCI in Taiwan. This is demonstrated in the industry analysis and the analysis of strengths, weaknesses, opportunities, and threats, also combined with KSFs and matrix analysis. In order for Taiwan to have a strong market position in the potential sectors, the following need to be completed:

\section{Government Has to Establish the Comprehensive Infrastructure}

Taiwan is considered to have a high-level, knowledge-based national economy but it still lacks a well-planned policy for DCI. As previously mentioned, high levels of capital investment and adequate financial support are the characteristics of DCI; however, regulation of venture capital limits the funding support. Both government and private sector funds are needed to build the world-class infrastructure network.

\section{Enhancing the Link among Academic-Government-Industry}

Talent is an indispensable factor in constructing infrastructure for industry, especially high intellectual capital, and this is still a weakness for Taiwan. Any field in DCI needs skilled talent for innovation and new design.

\section{Triple Play is the Mainstream in BWA and Multimedia Market}

Triple play is the integration of "Data," "Voice," and "Video," and it could be the most practical application on the next generation network (NGN). Telecommunications, ISP, and equipment vendors must all commit to developing new products for NGN. Sufficient bandwidth will offer good quality of service so the mobile services, multimedia eLearnings, and digital archives sharing can be utilized on it.

\section{More Access for Owned Materials and Value Identification Support}

Digital archives need to provide materials and build a database to the other fields like mobile services or animation for Taiwan to achieve a competitive advantage. For the China market, easy reading and usage and attractive design are important to DCI products. Taiwan DCI vendors should access this strength for competing with Korea, Japan, or Western countries. Taiwan is at the critical position for the transition of Chinese content. DCI in Taiwan has many factors and barriers to consider, like resource allocation, financial support, and technology innovation. The government should understand the industries' needs and help bridge the relationship between industries, talent pools, and markets. The output of digital content is very subjective and unique, so the mechanism of value identification should be established.

Lastly, improvement of the business environment should be a focus for policy making. DCI is highly capital intensive, and the government needs to assist the development of the industry by setting appropriate policies, especially the financial support and the establishment of a transaction platform for capturing resources 
and promoting output. DCI is now included in Taiwan's economic plan and has close links with the government, industries, and market. The market should be developed to gain more competitive advantages in the global market.

\section{Note}

1 Dynamism indicates the rate of change in the industry, the unpredictability of the behavior of customers and competitors, and the shifts in the industry's technological conditions (Zahra, 1993). Hostility creates an unfavorable climate, featuring intense competition for limited resources or market opportunities (Zahra, 1996). Heterogeneity indicates the diversity of the market segments in which the company operates (Zahra, 1991).

\section{About the Authors}

Hsin-Hann Tsai now is a doctoral student of Institute of Management Technology at National Chiao Tung University, and is the special assistant of the CEO of the Arcadyan Company. $\mathrm{He}$ is majoring in policy analysis and industrial and technology foresight.

Hong-Yuh Lee is currently the CEO of Arcadyan Technology Corporation, which is a leading company in broadband residential router product for triple play application. His current research interests include policies, business strategies, and startups.

Hsiao-Cheng Yu is Professor in the Institute of Technology Management, National ChiaoTung University, Taiwan. His current research interests include regulations, policies, and business strategies.

\section{References}

Abramovitz, M., \& David, P. A. (2000). American macroeconomic growth in the era of knowledge-based progress: The Long-Run perspective. In S. L. Engerman \& R. E. Gallman (Eds.), The Cambridge Economic History of the United States (Vol. 2, pp. 1-92). New York: Cambridge University Press.

Afuah, A. (1998). Innovation management: Strategies, implementation, and profits. London: Oxford University Press.

Allen Consulting Groups. (2003). Digital content: Creativity plus connectivity. Australia: Author.

Cheng, H. C., \& Shyu, J. Z. (2004). Innovation intensive service as actors of platform strategy adapted to emerging industry development. Paper presented at Portland International Conference on Management of Engineering and Technology '04, Seoul, Korea.

DCMS Creative Industries Task Force. (1998). Creative industries: Mapping document. London: Author.

Digital Content Promotion and Development Office (DCPDO). (2005). Taiwan Digital Content Industries. Working paper, MOEA.

Drake, G. (2005). This place gives me space: Place and creativity in the creative industries. Geoforum, 34, 511-524.

Griliches, Z. (1990). Patent statistics as economic indicators: a survey. Journal of Economic Literature, 28, 16611697.

Griliches, Z. (1998). RED and productivity: The econometric evidence. Chicago: University of Chicago Press.

Hausman, J., Hall, B. H., \& Griliches, Z. (1984). Econometric models for count data with an application to the patents-R\&D relationship. Econometrica, 52, 909-938.

Heskett, J. L., Sasser, W. E., Jr., \& Schlesinger, L. A. (1997). The value profit chain: Treat employees like customers and customers like employees. New York: Free Press.

Hitt, M. A., Hoskisson, R. E., \& Kim, H. (1997). International diversification: effects on innovation and firm performance in product-diversified firms. Academy of Management Journal, 40, 767-798.

Hsiang, J., Chen, H. H., \& Cheng, D. F. (2002). The forecasting of digital archive's application in industry. Paper presented at conference by MOEA, Taiwan.

Ministry of Economic Affairs (MOEA). (2004). Working paper of Taiwan Digital Content Industries. Taiwan: Author. Ministry of Economic Affairs (MOEA). (2005). Working paper of Taiwan Digital Content Industries. Taiwan: Author. 
Organisation for Economic Co-operation and Development (OECD) (1996). Science, technology and industry outlook. Paris: Author.

Organisation for Economic Co-operation and Development (OECD) (2004). Innovation in the knowledge economy. Paris: Author.

PriceWaterhouseCoopers. (2004). Global entertainment and media outlook: 2004-2008. New York: Author.

Scott, A. J. (2000). The cultural economy of cities. London: Sage Publications.

Scott, A. J. (2003). Cultural-products industries and urban economic development: Prospects for growth and market contestation in global context. Working Paper: University of California, Los Angeles.

Scott, A. J., \& Storper, M. (2003). Regions, globalization, development. Regional Studies, 37(6-7), 579-593.

Scottish Enterprise. (1999). Creativity and enterprise: Scotland's creative industries: Exploiting intellectual property in the knowledge sector. Glasgow: Author.

Shyu, J. Z., Cheng, H. C., \& Lai, H. C. (2005). Interlinking the national systems of innovation and knowledge economy. Sci-Tech Policy Review [Science and Technology Information Center of Taiwan], 359-378.

Yusuf, S., \& Nabeshima, K. (2005). Creative industries in East Asia. Cities, 22(2), 109-122.

Zahra, S. A. (1991). Predictors and financial outcomes of corporate entrepreneurship: An exploratory study. Journal of Business Venturing, 6(4), 259-286.

Zahra, S. A. (1993). Environment, corporate entrepreneurship, and financial performance: A taxonomic approach. Journal of Business Venturing, 8, 319-340.

Zahra, S. A. (1996). Technology strategy and financial performance: Examining the moderating role of the firm's competitive environment. Journal of Business Venturing, 11, 189-219. 